\title{
CALL CENTRE BRIGADE SIAGA BENCANA SEBAGAI STRATEGI PELAYANAN KESEHATAN DI KABUPATEN BANTAENG
}

\author{
Nur Khaerah, Ahmad Harakan, Junaedi \\ Program Studi IImu Pemerintahan, Universitas Muhammadiyah Makassar \\ Jalan Sultan Alauddin No.259 Makassar 90221 Indonesia \\ email: Nurkhaerah@unismuh.ac.id
}

\begin{abstract}
Abstrak
Artikel ini bertujuan untuk mengetahui ada atau tidaknya kekuatan, kelemahan, ancaman dan peluang Brigade Siaga Bencana dalam memberikan pelayanan melalui call centre dan untuk mengetahui efektifitas Brigade Siaga Bencana dengan menggunakan strategi call centre. Jenis penelitian ini adalah deskriptif kualitatif dengan menggunakan dua macam data yaitu data primer dan data sekunder. untuk memperoleh data, peneliti melakukan observasi dengan pihak Dinas Kesehatan, Brigade Siaga Bencana, dan Masyarakat pada lokasi penelitian, dan wawancara dengan jumlah informan sebanyak 9 orang. Hasil penelitian ini menunjukkan bahwa kualitas pelayanan kesehatan masyarakat di Kabupaten Bantaeng menggunakan sistem call centre 133/119 PSC atau frekuensi Radio terbilang sudah cukup baik, namun masih terdapat beberapa hal yang perlu untuk ditingkatkan terutama dalam indikator teknologi agar kualitas pelayanan call centre Brigade Siaga Bencana bisa lebih efektif lagi dan adapun salah satu kekuatanya adalah sarana dan prasarana yang memadai, kelemahanya yaitu belum tersedianya alat pendeteksi lokasi penelpon atau call tracker, peluangnya karna besarnya keinginan masyarakat untuk menggunakan call centre Brigade Siaga Bencana dan yang menjadi ancaman Brigade Siaga Bencana adalah jaringan seluler yang tidak stabil di beberapa titik tertentu.
\end{abstract}

Kata kunci: siaga bencana, strategi, pelayanan kesehatan

\begin{abstract}
This article aims to determine whether or not there are strengths, weaknesses, threats and opportunities for the Disaster Preparedness Brigade in providing services through call centers and to find out the effectiveness of the Brigade by using call center strategy. This is descriptive qualitative research by using two types of data - primary and secondary data. To obtain data, the authors observed the Health Office, Disaster Alert Brigade, and the Community at the location of the study, and interviewed with 9 informants. The results of this study indicate that the quality of public health services in Bantaeng District uses the 133/119 PSC or Radio frequency system call fairly well, but there are still some things that need to be improved especially in technological indicators so that the quality service of the disaster alert Brigade call center can more effective and as for one of its strengths is adequate facilities and infrastructure, the weakness is the unavailability of a detection device for the location of callers or call tracker, the opportunity due to the public's willingness to use the Disaster Alert Brigade call center and the threat of the Disaster Alert Brigade is a cellular network unstable at certain points.
\end{abstract}

Keywords: disaster preparedness, strategy, health services

\section{PENDAHULUAN}

Pelayanan publik oleh pemerintah kepada masyarakat adalah tujuan utama yang tidak mungkin dapat dihindari. Publik selalu menuntut kualitas pelayanan publik dari 
birokrat, meskipun tuntutan ini tidak sesuai dengan harapan karena pelayanan publik secara empiris yang terjadi selama ini masih ditandai dengan hal-hal seperti berbelitbelit, lambat, mahal, ketidakpastian melelahkan (Mahsyar 2011).

Birokrasi merupakan instrumen pemerintah dalam menyelenggarakan pelayanan dengan menciptakan pelayanan yang terbaik kepada masyarakat. Manajemen profesional pelayanan publik harus lebih berorientasi pada tujuan paradigma pemerintahan yang didasarkan pada pendekatan manajemen baru, baik secara teori maupun praktis (Usman 2011). Karena telah menjadi suatu kewajiban, maka sepatutnya pemerintah mencari sebuah solusi yang terbaik terhadap kendalakendala yang sering dihadapi, termasuk kendala yang datangnya dari masyarakat itu sendiri sebagai pengguna jasa dalam kaitanya dengan pelayanan umum yang ditangani oleh birokrasi. Selain itu, birokrasi harus senantiasa memberikan pelayanan dengan sebaik-baiknya kepada masyarakat secara keseluruhan sehingga menghasilkan pelayanan yang baik.

Pelayanan publik oleh negara melalui pemerintah dan dilaksanakan oleh aparat birokrasi sekarang telah berada di era globalisasi, kemajuan teknologi informasi dan komunikasi (TIK) yang demikian pesat, memudahkan komunikasi antar masyarakat di dunia tanpa perlu mediator dan tanpa mengenal batasan (negara, suku dan agama). Transformasi birokrasi menjadi keharusan. Salah satu cara transformasi birokrasi dalam pelayananpublik adalah penerapan teknologi informasi dan komunikasi dalam pelayanan publik (Supardal 2016). Masyarakat juga telah banyak mengenal arti pentingnya teknologi, dan kualitas kehidupan masyarakat telah meningkat, peningkatan kualitas kehidupan masyarakat menyebabkan tuntutan standar pelayanan.

Menurut Ely Sufianty (2006) dalam Endah (2012) rendahya kualitas pelayanan terjadi hampir pada semua aspek pelayanan publik, baik pada aspek pelayanan jasa, administrasi dan pelayanan barang. Untuk mengatasi permasalahan tersebut dan sejalan dengan perkembangan teknologi informasi, Salah satu upaya yang dilakukan oleh pemerintah daerah Kabupaten Bantaeng dalam meningkatkan pelayanan publik khususnya pelayanan kesehatan bagi masyarakat dengan memberikan pelayanan baru berbasis ternologi kepada masyarakatya yaitu pelayanan kesehatan melalui via telepon selular (call centre) maupun frekuensi radio Brigade Siaga Bencana. Pelayanan kesehatan berbasis perangkat telekomunikasi, 
diterapkan oleh pemerintah Kabupaten Bantaeng akibat selain dari adanya tuntutan atau kemajuan dari teknologi itu sendiri dan kebutuhan masyarakat yang makin lama makin meningkat dan membutuhkan kecepatan dalam pelayanan, maka pelayanan publik juga harus terus mengalami transformasi dalam bidangnya, salah satunya dalam teknologi itu sendiri.

Penerapan teknologi dalam pelayanan publik merupakan sebuah tuntutan dan kewajiban bagi pemerintah untuk melaksanakannya sesuai dengan Keppres No.3 tahun 2003 tentang kebijakan dan strategi nasional pengembangan epemerintahan dan pelayanan publik berdasarkan pada Undang-Undang No.25 Tahun 2009, aturan tersebut pada intinya adalah meningkatkan kualitas pelayanan publik, yang efisien dan transparan, serta banyak manfaat positif lainya, maka layanan berbasis teknologi pun merupakan sesuatu yang perlu dilakukan oleh organisasi pemerintah.

Merujuk pada Keppres No.3 Tahun 2003 dan Undang-Undang (UU) No.25 Tahun 2009, diatas maka pemerintah Kabupaten Bantaeng membuat sebuah inovasi yaitu emergency service, dan didalam emergency service terdapat beberapa bagian yaitu Brigade Siaga Bencana (BSB), tagana (taruna siaga bencana), SAR, PMI, ORARI, dan pemadam kebakaran (Damkar). Dan sebagai daerah otonom pemerintah Kabupaten Bantaeng membuat Peraturan Daerah No.10 Tahun 2008, yang pada intinya peraturan tersebut adalah mengenai pelayanan kesehatan bagi masyarakat di Kabupaten Bantaeng, yang akan menjadi titik fokus penulis yaitu Brigade Siaga Bencana (BSB).

Pada dasarnya setiap kebijakan yang dikeluarkan oleh pemerintah harus mempunyai beberapa persiapan, agar berjalan sesuai dengan harapan yang diinginkan begitupun dengan inovasi yang dikeluarkan oleh pemerintah Kabupaten Bantaeng. Dalam memulai pembentukan Brigade Siaga Bencana terdapat dua tahapan dalam memulai proses pengoporasiannya yaitu: Pengadaan infrastruktur sarana dan prasarana seperti peralatan kesehatan dan pengadaan transportasi atau ambulance. Saat ini Brigade Siaga Bencana memiliki lima unit mobil ambulace yang berasal dari dinas kesehatan Bantaeng (satu unit), bantuan dari asuransi kesehatanAskes (satu unit), dan bantuan dari pemerintah Jepang (tiga unit), satu dar itiga unit bantuan tersebut di fasilitasi alat monitor pemeriksaaan jantung dan peralatan medis yang memadai. Selain itu terdapat dua unit speed boat milik tim SAR yang sewaktu- 
waktu dapat dipakai tim Brigade Siaga Bencana bila ada korban atau pasien di laut dan persiapan sumber daya manusia yang memadai, dengan cara melakukan pelatihan-pelatihan ketanggap daruratan. Pelatihan bagi dokter adalah pelatihan general emergency life support dan bagi perawat adalah pelatihan basic trauma cardiac life support. Kedua jenis pelatihan tersebut dimaksudkan untuk memberikan pengenalan dan pengetahuan bagi tenaga medis dalam hal tanggap darurat.

Hal yang menjadi dasar di bentuknya Brigade Siaga Bencana karena melihat kondisi sosial masyarakat masih tradisional dan melihat pelayanan kesehatan masyarakat masih kurang efektif maka Nurdin Abdullah selaku bupati kabupaten Bantaeng berinisiatif membuat pusat penanganan darurat yaitu Brigade Siaga Bencana (BSB), merupakan konsep untuk menangani situasi kritis dengan basis emergency dan komunitas (Tamimi 2015). Sifat emergency berarti konsep layanan tersebut mengutamakan cepat siaga, sedangkan komunitas untuk memberi arti bahwa layanan tersebut diperuntukkan bagi masyarakat. Keistimewaan Brigade Siaga Bencana adalah mekanisme untuk mendekatkan pelayanan dasar kesehatan kepada seluruh masyarakat di Kabupaten Bantaeng. Brigade Siaga Bencana ini terbentuk pada 7 Desember 2009 yang bertepatan dengan hari ulang tahun Kabupaten Bantaeng yang ke-755, BSB ini bertujuan memberikan pelayanan kesehatan terdepan dan tercepat atas setiap bencana/musibah yang menimpa masyarakat. Keberadaan Brigade Siaga Bencana diperlukan sebagai upaya kesiapsiagaan dalam penanggulangan setiap bencana atau musibah terutama bagi masyarakat yang memerlukan pertolongan cepat namun jauh dari jangkauan dokter maupun terkendala masalah transportasi karena tidak memiliki kendaraan.

Dalam pengertian umum Brigade Siaga Bencana ialah untuk merespon kejadian bencana di suatu wilayah, keberadaanya terdapat diberbagai daerah yang dianggap sebagai crisis centre terutama dalam menghadapi bencana Berbeda dari penerapanya Brigade siaga bencana di Kabupaten Bantaeng adalah kondisi krisis yang tidak diterjemahkan dalam kondisi bencana saja. Tetapi saat kondisi sakit dan musibah biasa dianggap sebagai keadaan darurat, misalnya persalinan, kebakaran, kecelakaan dan kondisi darurat lainya.

Mengingat layanan Brigade Siaga Bencana ini relative masih baru sehingga diperlukan suatu standar prosedur yang menjadi acuan bagi seluruh petugas BSB dalam memberikan layanan bagi masyarakat. Standar prosedur layanan brigade 
siaga bencana ini menggunakan system layanan call centre 113 atau 119 dan (0413) 22724 atau melalui frekuensi radio $145.490 \mathrm{MHz}$. Setelah mendapatkan laporan, maka tim BSB segera mendatangi pasien, setelah memeriksa pasien maka tim BSB memberikan diagnosa apakah dapat dirawat jalan dengan memberikan obat di rumah, dibawah ke kantor BSB untuk mendapatkan layanan lebih lanjut atau di rujuk ke puskesmas setempat dan rumah sakit umum daerah (RSUD).

Menurut Albrecht dan Zemke (1990) dalam Dwiyanto (2008) kualitas pelayanan publik merupakan hasil interaksi dari berbagai aspek yaitu sistem pelayanan, sumber daya manusia, pemberi layanan, strategi dan pelanggang (customers), oleh karena itu menilik hasil observasi awal dan hasil penelitian terdahulu yang dilakukan oleh Nurfaq (2016) berjudul analisis layanan kesehatan bebas retribusi di Kabupaten Bantaeng pada masalah pelayanan kesehatan bebas retribusi di Kabupaten Bantaeng dengan tujuan untuk mengetahui strategi inovasi pelayana kesehatan bebas retribusi di Kabupaten Bantaeng, lain halnya dengan penulis, penulis lebih berfokus pada pelayanan call centre Brigade Siaga Bencana Kabupaten Bantaeng, dengan tujuan untuk mengetahui ada atau tidaknya kekuatan, kelemahan, peluang dan ancaman Brigade Siaga Bencana Kabupaten Bantaeng serta untuk mengetahui efektifitas pelayanan kesehatan Brigade Siaga Bencana melalui call centre. Karena penulis melihat bahwa Kabupaten Bantaeng merupakan daerah yang mempunyai karakteristik wilayah yang beraneka ragam, ada yang berdomisili di pedesaan dan ada pula berada di dataran tinggi sehingga memungkinkan pelayanan Brigade Siaga Bencana kurang efektif dan tidak sesuai dengan prosedur.

Berdasarkan hal tersebut diatas, maka artikel ini bertujuan untuk memberi pemahaman tentang keberadaan Call Centre Brigade Siaga Bencana sebagai strategi pelayanan kesehatan masyarakat di Kabupaten Bantaeng.

\section{METODE PENELITIAN}

Penelitian ini menggunakan jenis penelitian kualitaif dan tipe penelitian deskriptif akan dilakukan di Kabupaten Bantaeng. Topik yang diteliti adalah call cantre Brigade Siaga Bencana Sebagai Strategi Pelayanan Kesehatan di Kabupeten Bantaeng. Dengan melakukan Observasi dan wawancara dengan beberapa informan yang 
telah ditentukan yaitu Koordinator umum call centre, Koordinator harian call centre, Bendahara call centre, Tim medis, Operator, dan Tokoh Masyarakat.

\section{PEMBAHASAN}

Sistem kesehatan di Indonesia tidak terlepas dari pembangunan pelayanan kesehatan, intinya pelayanan kesehatan merupakan seluruh aktifitas uang mempunyai tujuan utama untuk mempromosikan mengembalikan dan memelihara kesehatan denagan distribusi yang adil bagi masyarakat sistem pelayanan kesehatan tidak hanya menilai dan memfokus kepada pada tingka yang diberikan, tetapi juga bagaimana manfaat itu dilakukan pemerintah untuk melaksanakan pelayanan kesehatan (M. Tahir \& Harakan 2018). Maka Pembangunan bidang kesehatan di kabupaten Bantaeng di arahkan agar pembangunan kesehatan lebih meningkat, lebih luas, lebih merata dan terjangkau oleh lapisan masyarakat. Kesehatan merupakan bagian yang terpenting dan diharapkan dapat menghasilkan derajat kesehatan yang lebih tinggi dan memungkinkan setiap orang hidup produktif secara sosial maupun ekonomis. Penyediaan sarana pelayanan kesehatan berupa rumah sakit, puskesmas dan tenaga kesehatan semakin ditingkatkan jumlahnya sesuai dengan rencana pentahapannya.

Adapun sarana pelayanan kesehatan di kabupaten Bantaeng pada tahun 2014 telah tersedia rumah sakit umum sebanyak 1 buah, puskesmas/pustu/puskesmas keliling 12 buah. Jumlah dokter umum sebanyak 4 orang, bidan, 60 orang, apotik 8 buah, dan jumlah tenaga kesehatan pada tahun 2014 sebanyak 125 orang.

Salah satu tujuan pembangunan khususnya pembanguanan sumber daya manusia (SDM) adalah terciptanaya kehidupan masyarakat yang sehat, beriman dan menguasai teknologi. Sehingga melahirkan generasi penerus yang lebih baik. Usaha pemerintah daerah untuk meningkatkan pelayanan kesehatan dilakukan secara optimal sesuai dengan kemampuan daerah, disamping juga meminta bantuan dari luar dan dalam negeri. Usaha tersebut telah membuahkan hasil yang dapat dirasakan oleh masyarakat sehingga akses pelayanan kesehatan dapat dirasakan sampai wilayah pedesaan.

Untuk mengukur keberhasilan atau kinerja pembangunan manusia di suatu wilayah atau negara saat ini yang digunakan UNDP adalah menghitung indeks pembangunan manusia (IPM) dan mulai tahun 2014 dihitung dengan menggunakan 
metode baru. Metode IPM dengan metode baru adalah angka harapan hidup, pendidikan atau pengetahuan, dan standar hidup layak. Angka harapan hidup dihitung berdasarkan variabel rata-rata anak lahir hidup dan rata-rata anak yang masih hidup. Pengetahuan diukur dengan angka indeks rata-rata lama sekolah dan indeks harapan lama sekolah. Sedangkan indikator daya beli diukur dengan indikator rata-rata komsumsi ril yang telah disesuaikan.

IPM kabupaten Bantaeng tahun 2014 mencapai 65,77 dan berada pada peringkat 16. Dengan IPM metode baru peringkat kabupaten Bantaeng pada tahun 2013 dan tahun 2014 berada pada peringkat 16 dari 24 kabupaten/kota di Sulawesi selatan. Hal ini menggambarkan bahwa adanya keberhasilan dalam perbaikan pelayanan kesehatan, pendidikan dan daya beli masyarakat di kabupaten Bantaeng.

Brigade siaga bencana (BSB) sebagai salah satu unit yang menyelenggarakan pelayanan publik di Kabupaten Bantaeng. Salah satu jenis layanan yang di selenggarakan adalah pelayanan kesehatan dengan mengunakan sistem call centre. Untuk mengetahui bagaimana kualitas call centre yang digunakan oleh brigade siaga bencana ini kita dapat melihatnya dari beberapa indikator berikut:

\section{Sarana dan Prasarana}

Sarana adalah segala sesuatu yang dapat dipakai sebagai alat dalam mencapai maksud dan tujuan. Sedangkan prasarana adalah segala sesuatu yang merupakan penunjang utama terselenggaranya sesuatu proses usaha. Untuk lebih memudahkan membedakan keduanya sarana lebih ditujukan kepada benda-benda yang bergerak seperti computer dan mesin-mesin, sedangkan prasarana lebih ditujukan kepada benda-benda yang tidak bergerak seperti gedung. Sesuai dengan hasil penelitian menunjukkan bahwa sarana serta prasana yang dimiliki oleh Brigade Siaga Bencana itu sudah sangat memadai itu dapat dilihat dari beberapa fasilitas yang dimiliki seperti komputer, jaringan LAN dan wifi, mobil ambulance telepon, serta prasarana yang memadai seperti tersedianya ruangan call centre, ruang poli umum, ruang rapat, ruang observasi dan kantor-kantor cabang Brigade Siaga Bencana dibeberapa kecamatan di Kabupaten Bantaeng.

Brigade Siaga Bencana merupakan salah satu unit yang menyelenggarakan pelayanan publik di kabupaten Bantaeng yaitu pelayanan kesehatan dengan 
menggunakan sistem call centre maka dari itu sarana dan prasarana sangat penting untuk diperadakan dan dilengkapi agar pelayanan yang diberikan kepada masyarakat bisa lebih maksimal. Dengan pertimbangan itulah pemerintah Kabupaten Banteng berupaya melengkapi fasilitas Brigade Siaga Bencana baik itu sarananya maupun prasarananya, dan sampai saat ini sarana dan prasarana yang dimiliki brigade siaga bencana sudah sangat memadai baik itu fasilitas yang ada bagian call centre maupun di bagian medis. seperti yang dikatakan oleh ibu Ismu Istiqamah selaku operator call centre.

"sarana dan prasarananya di kantor Brigade Siaga Bencana ini sudah cukup memadai. Sudah ada beberapa telpon yang bisa di hubungi masyarakat dan ruangan untuk operator call centre juga ada di sini."

\section{Sumber Daya Manusia}

Pegawai merupakan salah satu kunci pokok dalam pelaksanaa tugas atau pekerjaan dalam suatu organisasi untuk melaksanakan tuntutan tugas atau pekerjaan. Berhubungan dengan sumber daya manusia yang dimiliki oleh Brigade Siaga Bencana sudah sangat baik, hal itu berdasarkan atas beberapa data wawancara dengan sejumlah informan yang mengatakan bahwa sudah ada beberapa pegawai yang sudah mengikuti pelatihan-pelatihan ketanggap daruratan, baik itu dari tim dokter, perawat, operator, sopir maupun cleaning servisnya.

Adapun jumlah dokter yang dimiliki oleh Brigade Siaga Bencana ada sebanyak 20 orang dan mereka telah mengikuti beberapa pelatihan ketanggap daruratan seperti pelatihan Anvanced trauma life support (ATLS), advanced cardiac life support (ACLS), general emergency life support (GELS) dan elektrokardiografi (EKG). Sedangkan perawat berjumlah 26 orang dan telah mengikuti pelatihan basic trauma life support and basic cardiac life support (BTCLS), dan 5 orang tim operator call centre dan juga telah mengikuti pelatihan ketanggap daruratan seperti pelatihan medical first responder (MFR), begitupun dengan sopir ambulans yang berjumlah 5 orang dan cleaning servis brigade siaga bencana yang berjumlah sebanyak 2 orang meraka juga telah mengikuti pelatihan MFR, pihak Brigade Siaga Bencana juga mengikut sertakan masyarakat umum sebanyak 40 orang dalam membantu kelancaran proses pelayanan kesehatan di Kabupaten Bantaeng. 


\section{Teknologi}

Di zaman modern seperti sekarang teknologi merupakan kebutuhan bagi setiap organisasi atau instasi baik itu instasi pemerintahan maupun swasta ,untuk mendukung proses pelayanan agar pelayanan jauh lebih cepat dari sebelumnya. Oleh sebab itu pemerintah Kabupaten Bantaeng mencoba menerepkannya di bidang kesehatan yaitu layanan bebas pulsa atau sering disebut call centre Brigade Siaga Bencana tujuannya yaitu itu untuk memudahkan masyarakat dalam mengakses layanan kesehatan di Kabupaten Bantaeng dan itu terbukti efektif dan bisa mengefesien waktu pelayanan. Seperti yang dikatakan bapak Taufik Hidayat selaku Koordinator call canter dalam wawancara dengan saya :

"Disini menerapkan sistem call centre bebas pulsa dan frekuensi Radio dan itu sangat membantu masyarakat tapi disisi lain call centre belum terlalu efektif sebab alat call tracker belum tersedia sehingga sulit mendeteksi lokasi penelpon".

Pemanfaatan teknologi untuk pelayanan yang lebih baik sudah dapat diterapkan oleh pemerintah Kabupaten Bantaeng dan itu dapat dilihat dari pemanfaatan teknologi berupa layanan call centre yang diterapkan oleh Brigade Siaga Bencana Kabupaten Bantaeng dan pada dasarnya teknologi yang dimiliki Brigade Siaga Bencana sudah cukup baik meski masih ada beberapa kekurangan yang perlu dilengkapi, hal ini didasarkan atas beberapa data yang diperoleh oleh peneliti baik data yang diperoleh dari tim Brigade Siaga Bencana maupun data yang diperoleh dari beberapa masyarakat.

\section{Informasi}

Informasi sangat dibutuhkan oleh Brigade Siaga Bencana melalui call centre untuk menciptakan pelayanan kesehatan yang efektif begitupun dengan masyarakat, mereka juga sangat membutuhkan informasi agar masyarakat dapat mengakses pelayanan Brigade Siaga Bencana, berdasarkan hal tersebut maka peneliti memilih 2 sub indikator sebagai tolak ukur pendekatan ini, yaitu: sosialisasi dan respon.

Sosialisasi adalah salah satu sub bagian dari indikator informasi, yaitu untuk mengetahui sejauh mana sosialisasi Brigade Siaga Bencana untuk memberikan 
pemahaman kepada masyarakat mengenai sistem pelayanan kesehatan yang bisa diakses melalui telpon seluler ataupun frekuensi radio.

Pihak Brigade Siaga Bencana mensosialisasikan layanana call centre kepada masyarakat dengan cara mengunjungi rumah ibadah seperti masjid, memasang reklame di pinggir jalan dan juga melibatkan rekan-rekanya tim medis di puskesmas ataupun pustu untuk mensosialisasikan layanan brigade siaga bencana tersebut, dan cara seperti itu dianggap berhasil sebab masyarakat yang menggunakan layanan Brigade Siaga Bencana sudah bertambah dari tahun pertama terbentuknya layanan call centre, itu menandakan bahwa masyarakat sudah paham mengenai prosedur pelayanan Brigade Siaga Bencana.

Respon merupakan sub indikator dari bagian informasi, yaitu untuk melihat sejauh mana responsivitas tim call centre maupun personil lain ketika mendapatkan laporan dari masyarakat. Responsivitas sangat di perlukan dalam melakukan pelayanan kepada masyarakat terutama dalam pelayanan ketanggap daruratan karena kalau misalkan ada masyarakat yang mengalami kecelakaan dan pihak Brigade Siaga Bencana lambat dalam respon laporan masyarakat, korban kecelakaan sangat rawan mengalami kematian karna terlambat ditagani.

Akan tetapi pihak Brigade Siaga Bencana telah mengantisipasi kejadiankejadian seperti itu dengan menerapkan pelayanan safety selama 24 jam. Seperti yang dikatakan oleh bapak Taufik Hidayat selaku Koordinator call centre.

" disini kita dituntut oleh atasan untuk selalu safety selama 24 jam, kalau tim call canter itu mendengar telponya berbunyi dia harus langsung mengangkat telponnya dan menanyakan data diri si penelpon dan keadaan pasien dan setelah tim call centre mendapatkan data si penelpon dan pasien maka operatornya langsung mengkonfirmasikan ke tim medis".

Respon time sebaiknya harus selalu ditingkatkan, tentunya dengan mempertimbangkan kualitas pelayanan dan keselamatan. Logikanya semakin cepat respon time semakin baik, akan tetapi kualitas pelayanan dan keselamatanlah yang utama. Respon time yang terlalu cepat juga terkadang berbahaya karena akan menimbulkan masalah baru, misalnya mobil ambulans mengalami kecelakaan karena terburu-buru. Jadi sebaiknya respon time disesuaikan dengan standar keaman. 


\section{Analisis SWOT}

Analisis SWOT digunakan untuk mengkaji faktor yang menjadi kekuatan (strength), kelemahan (weaknesses), peluang (opportunities), dan ancaman (threats) yang dihadapi dalam meningkatkan kualitas pelayanan kesehatan melalui call centre Brigade Siaga Bencana Kabupaten Bantaeng.

Selain itu ada faktor internal dan eksternal yang sangat mempengaruhi kesuksesan pelaksanaan program ini. Pada faktor internal, call centre Brigade Siaga Bencana dalam melakukan pelayanan kesehatan terdapat beberapa faktor yang mempengaruhi antara lain adalah faktor kekuatan dan faktor kelemahan. Faktor kekuatan yaitu sarana dan prasarana yang menunjang dalam melakukan pelayanan kesehatan kepada masyarakat. Dikategorikan ke dalam faktor kekuatan dikarenakan sarana dan prasarana yang dimiliki Brigade Siaga Bencana Kabupaten Bantaeng sangat menunjang dalam melakukan pelayanan kesehatan melalui call centre. Bisa dilihat dari komputer yang disediakan untuk operator call centre, sumber daya manusia yang dimiliki oleh Brigade Siaga Bencana Kabupaten Bantaeng itu sudah sangat memadai itu dapat dilihat dari jumlah personil yang dimiliki dan tidak sekedar jumlahnya saja yang banyak akan tetapi para pegawai di Brigade Siaga Bencana Kabupaten Bantaeng sebagian besar telah mengikuti pelatihan-pelatihan ketanggap daruratan dan itu sangat membantu dalam mewujudkan kualitas pelayanan prima, dan call center Brigade Siaga Bencana mempercepat waktu pelayanan kesehatan. Dikatakan seperti itu karena masyarakat bisa langsung menelpon ke 113/119 ataupun frekuensi radio. Sebelum adanya call centre masyarakat kerepotan ketika ada orang yang membuthkan perawatan medis karena mereka harus ke puskesmas terdekat untuk meminta bantuan mobil ambulans dan jika mobilnya ada di tempat.

Faktor kelemahan yaitu belum adanya alat call tracker yang dimiliki oleh Brigade Siaga Bencana Kabupaten Bantaeng sehingga operator call centre tidak bisa mendeteksi lokasi penelpon sehingga operator call centre harus menanyakan langsung kepada penelpon di mana lokasinya.

Sedangkan pada faktor eksternal, call centre Brigade Siaga Bencana Kabupaten Bantaeng dalam melakukan pelayanan kesehatan di Kabupaten Bantaeng terdapat beberapa faktor yang mempengaruhi pelayanan yaitu faktor peluang dan faktor ancaman. 
Faktor peluang yaitu keinginan masyarakat untuk mengunakan layanan call centre Brigade Siaga Bencana Kabupaten Bantaeng meningkat. Dikatakan seperti itu karena sejak awal dibentuknya Brigade Siaga Bencana dengan menerapkan sistem call centre pada tahuin 2009. Jumlah masyarakat yang menggunakan layanan Brigade Siaga Bencana ini setiap tahunnya bertambah, dan infrastruktur yang ada di Kabupaten Bantaeng sangat memadai sehingga sangat membantu Brigade Siaga Bencana dalam menjemput pasien yang membutuhkan pertolongan medis, dan itu dapat dilihat dari respon time yang kurang dari 30 menit.

Faktor ancaman yaitu jaringan selular yang tidak stabil dan itu bisa menjadi ancaman terbesar bagi call centre Brigade Siaga Bencana karena jika jaringan kurang bagus masyarakat kesulitan dalam mengakses call centre 113/119 psc Kabupaten Bantaeng begitupun sebaliknya jika jaringan di kantor Brigade Siaga Bencana mengalami gangguan maka secara otomatis telpon dari masyarakat tidak dapat terhubung ke call centre Brigade Siaga Bencana Kabupaten Bantaeng.

\section{KESIMPULAN}

Berdasarkan hasil penelitian dan pembahasan tentang rumusan masalah yang telah diuraikan pada bab sebelumnya maka penulis menyimpulkan bahwa kualitas pelayanan kesehatan masyarakat di Kabupaten Bantaeng melalui call centre Brigade Siaga Bencana pada dasarnya sudah cukup baik, namun masih terdapat beberapa hal terutama dalam indikator teknologi yang masih perlu untuk ditingkatkan agar kualitas pelayanan call centre Brigade Siaga Bencana bisa lebih efektif lagi. Upaya Brigade Siaga Bencana menerapkan layanan kesehatan kepada masyarakat Kabupaten Bantaeng dengan menggunakan sistem call centre 133/119 PSC atau frekuensi Radio terbilang sudah cukup baik, namun masih perlu untuk di tingkatkan lagi.

Faktor-faktor yang dihadapi dalam meningkatkan kualitas pelayanan kesehatan melalui Brigade Siaga Bencana di Kabupaten Bantaeng, yaitu Faktor internal dan faktor eksternal. Faktor internal yaitu berupa kekuatan dan kelemahan. adapun kekuatan yang dimiliki Brigade Siaga Bencana yaitu sarana dan prasarana yang menunjang, sumber daya yang memadai dan call centre Brigade Siaga Bencana mempercepat waktu pelayanan. Adapun kelemahanya yaitu belum adanya 
call tracker yang dimiliki oleh call centre Brigade Siaga Bencana Kabupaten Bantaeng.

Faktor eksternal yaitu berupa peluang dan ancaman. adapun peluang Brigade Siaga Bencana adalah infrastruktur yang ada di Kabupaten Bantaeng sangat memadai dan keinginan masyarakat mengunakan layanan call centre Brigade Siaga Bencana Kabupaten Bantaeng. Adapun ancaman call centre Brigade Siaga Bencana yaitu tidak stabilnya jaringan selular di beberapa desa di Kabupaten Bantaeng sehingga masyarakat yang ingin mengunakan layanan call centre Brigade Siaga Bencana tidak bisa terhubung dengan operator call centre Brigade Siaga Bencana akbibat jaringan selular yang tidak stabil.

\section{REFERENSI}

Dwiyanto, A. (Ed.). (2005). Mewujudkan good governance melalui pelayanan publik. Gadjah Mada University Press.

Endah E.S. 2012. Pemanfaatan e-government dalam pelayanan publik di Indonesia.http://blog.pasca.gunadarma.ac.id/2012/11/19/pemanfaatanegover nment-dalam-pelayanan-publik-di-indonesia-oleh-endaekasetawati41-mmsi2/ diakses 25 oktober 2018, pukul 11.23 WITA).

Mahsyar, A. (2011). Masalah Pelayanan Publik di Indonesia dalam Perspektif Administrasi Publik. Otoritas: Jurnal Ilmu Pemerintahan, 1(2).

Nurhaq, M. 2016. Analisis layanan kesehatan bebas retribusi di Kabupaten Bantaeng. Master Thesis Universitas Hasanuddin: Makassar.

Supardal, S. (2016). Penerapan ICT dalam Pelayanan Publik di Kabupaten Bantul. Otoritas: Jurnal IImu Pemerintahan, 6(2), 120-134.

Tahir, M. M., \& Harakan, A. (2018). Inovasi Program Kesehatan 24 Jam Dalam Mewujudkan Good Health Care Governance di Kabupaten Bantaeng. JURNAL MUQODDIMAH : Jurnal IImu Sosial, Politik dan Hummaniora, 2(1).

Tamimi, Z. (2015). Inovasi Manajemen Pelayanan Publik Tim Emergency Service Kabupaten Bantaeng. Politika: Jurnal IImu Politik, 6(1), 141-158. 
Jurnal Dinamika Pemerintahan

Vol.2, No. 1 (Januari 2019)

Hal. 51-64

Usman, J. (2011). Manajemen Birokrasi Profesional dalam Meningkatkan Pelayanan Publik. Otoritas: Jurnal IImu Pemerintahan, 1(2). 